\title{
Post-operative cardiovascular complications and time to recurrence in meningioma patients treated with versus without pre-operative embolization: a retrospective cohort study of 741 patients
}

Wirsching, Hans-Georg ; Richter, Johannes Konstantin ; Sahm, Felix ; Morel, Corinne ; Krayenbuehl, Niklaus ; Rushing, Elisabeth Jane ; von Deimling, Andreas ; Valavanis, Antonios ; Weller, Michael

\begin{abstract}
PURPOSE Preoperative embolization of radiographically suspected meningiomas is often performed to facilitate tumor resection. Its effects on the subsequent disease course of meningioma patients have not been studied in detail and randomized trials are lacking. The purpose of this study was to explore associations of preoperative meningioma embolization with postoperative outcome. PATIENTS AND METHODS Patients undergoing resection of an intracranial meningioma at the University Hospital Zurich 2000-2013 ( $\mathrm{N}=741$ ) were reviewed for the inclusion of pre-operative embolization in the management strategy. Annotations included demographics, radiographic, surgical, histological and hematological parameters, cardiovascular risk factors, pre- and postoperative neurological function and gene methylation-based classification. Binary regression and Cox proportional hazards models were applied to determine factors associated with outcome. RESULTS Pre-operative embolization was performed in 337 patients (42\%). Cardiovascular events after surgery comprised mostly deep vein thrombosis $(\mathrm{N}=39)$ and pulmonary embolisms $(\mathrm{N}=64)$. On multivariate analyses of post-operative cardiovascular adverse events controlling for established risk factors, there were associations with embolization (OR 2.38, 95\% CI 1.37-4.00), and with female gender (OR 2.18, 95\% CI 1.17-4.08). Recurrence-free survival (RFS) of embolized patients was less favorable among patients with WHO grade II or grade III meningiomas (median RFS: 4.3 vs. 7.0 years, $\mathrm{P}=0.029)$ or in patients with intermediate or malignant gene methylation subtype meningiomas (median RFS: 2.0 vs. 8.2 years, $\mathrm{P}=0.005$ ). CONCLUSION Pre-operative meningioma embolization may cause adverse outcomes. Randomized trials to determine benefit-risk ratios are warranted to clarify the role of pre-operative embolization for the treatment of meningioma patients.
\end{abstract}

DOI: https://doi.org/10.1007/s11060-018-2996-0

Posted at the Zurich Open Repository and Archive, University of Zurich

ZORA URL: https://doi.org/10.5167/uzh-153720

Journal Article

Accepted Version

Originally published at:

Wirsching, Hans-Georg; Richter, Johannes Konstantin; Sahm, Felix; Morel, Corinne; Krayenbuehl, Niklaus; Rushing, Elisabeth Jane; von Deimling, Andreas; Valavanis, Antonios; Weller, Michael (2018). Post-operative cardiovascular complications and time to recurrence in meningioma patients treated with versus without pre-operative embolization: a retrospective cohort study of 741 patients. Journal of Neuro-Oncology, 140(3):659-667.

DOI: https://doi.org/10.1007/s11060-018-2996-0 
Post-operative cardiovascular complications and time to recurrence in meningioma patients treated with versus without pre-operative embolization: a retrospective cohort study of 741 patients

Hans-Georg Wirsching, MD, ${ }^{1,}{ }^{*}$ Johannes Konstantin Richter, MD, ${ }^{2}$ Felix Sahm, MD, ${ }^{5}$ Corinne Morel, MD,${ }^{1}$ Niklaus Krayenbuehl, MD ${ }^{3}$ Elisabeth Jane Rushing, MD, ${ }^{4}$ Andreas von Deimling, $\mathrm{MD},{ }^{5}$ Antonios Valavanis, MD, ${ }^{2}$ Michael Weller, MD, ${ }^{1}$

Departments of ${ }^{1}$ Neurology, ${ }^{2}$ Neuroradiology, ${ }^{3}$ Neurosurgery and ${ }^{4}$ Neuropathology, University Hospital and University of Zurich, Zurich, Switzerland; ${ }^{5}$ Department of Neuropathology, University Hospital Heidelberg and Clinical Cooperation Unit Neuropathology, German Consortium for Translational Cancer Research (DKTK), German Cancer Research Center (DKFZ), Heidelberg, Germany; ${ }^{6}$ Department of Diagnostic, Interventional and Pediatric Radiology, Inselspital and University of Bern, Bern, Switzerland.

* Corresponding author: Hans-Georg Wirsching, MD, Department of Neurology, University Hospital Zurich and University of Zurich, Zurich, Frauenklinikstrasse 26, 8091 Zurich, Switzerland, Phone: +41-44-255-5500, Fax: +41-44-255-4507,

E-mail: hans-georg.wirsching@usz.ch

Running head: Postoperative outcome of meningioma embolization

Key words: embolism, embolization, meningioma, post-operative, recurrence, thrombosis Funding: None.

Conflicts of interest: The authors declare no potential conflicts of interest.

IRB No.: KEK-ZH-2014-0087

Words in abstract: $\quad 246$

Words in main body: $\quad 3210$

References: 24

Tables: 3

Figures: 2

Supplementary Tables: $\quad 8$ 
Supplementary Figures: $\quad 3$

\begin{abstract}
Purpose: Preoperative embolization of radiographically suspected meningiomas is often performed to facilitate subsequent tumor resection. Its effects on the subsequent disease course of meningioma patients have not been studied in detail and randomized trials are lacking. The purpose of this study was to explore associations of preoperative meningioma embolization with postoperative outcome.
\end{abstract}

Patients and Methods: Patients undergoing resection of an intracranial meningioma at the University Hospital Zurich 2000-2013 (N=741) were reviewed for the inclusion of pre-operative embolization in the management strategy. Annotations included demographics, radiographic, surgical, histological and hematological parameters, cardiovascular risk factors, pre- and postoperative neurological function and gene methylation-based classification. Binary regression and Cox proportional hazards models were applied to determine factors associated with outcome. Results: Pre-operative embolization was performed in 337 patients (42\%). Cardiovascular events after surgery comprised mostly deep vein thrombosis $(\mathrm{N}=39)$ and pulmonary embolisms $(\mathrm{N}=64)$. On multivariate analyses of post-operative cardiovascular adverse events controlling for established risk factors, there were associations with embolization (OR 2.38, 95\% CI 1.37-4.00), and with female gender (OR 2.18, 95\% CI 1.17-4.08). Recurrence-free survival (RFS) of embolized patients was less favorable among patients with WHO grade II or grade III meningiomas (median RFS: 4.3 versus 7.0 years, $\mathrm{P}=.029$ ) or in patients with intermediate or malignant gene methylation subtype meningiomas (median RFS: 2.0 versus 8.2 years, $\mathrm{P}=.005$ ). Conclusion: Pre-operative meningioma embolization may cause adverse outcomes. Randomized trials to determine benefit-risk ratios are warranted to clarify the role of pre-operative embolization for the treatment of meningioma patients. 


\section{Introduction}

Meningiomas are the most common primary intracranial tumors in adults [1]. The World Health Organization (WHO) classification of tumors of the central nervous system assigns grades I-III based on histological criteria [2]. WHO grade I meningiomas are histologically benign and commonly treated with surgery alone, whereas WHO grade II and III meningiomas are characterized by microscopic signs of atypia and malignancy, recur frequently and are therefore often treated with post-operative radiotherapy [3,4,2].

Pre-operative tumor embolization utilizing microparticles is often performed to reduce blood loss during surgery and facilitate resection. Since prospective efficacy studies are lacking, controversy exists as to whether the risk of an additional procedure is justified [5,6]. Skepticism also arises regarding the frequent observation of cellular atypia and mitotic activity in peri-necrotic areas after embolization, which may mislead neuropathologists to overestimate tumor grade and subsequently provoke unnecessary adjuvant treatment $[7,8]$.

Meningioma surgery is associated with moderate or severe morbidity in a substantial fraction of patients [9-12]. The risk of post-operative thrombosis and pulmonary embolism after meningioma resection exceeds that of other brain tumors $[13,14,11,12]$. Underlying causes that have been identified include duration of surgery, older age, comorbidities and surgical complications [12,11], but a potential role of pre-operative tumor embolization has not been studied in detail.

Here we report the post-operative outcomes in a cohort of 741 consecutive meningioma patients according to whether or not they underwent pre-operative embolization. Outcomes were assessed in multivariate models that control for established prognostic factors.

\section{Patients and Methods}

\section{Subject selection and study design}

Supplementary Figure 1 details the primary analysis population. A total of 779 consecutive patients that underwent neurosurgery for intracranial meningioma at the University Hospital Zurich between 2000 and 2013 were identified by an automated search of the electronic chart 
system [9] and classified based on whether pre-surgical tumor embolization was performed within 1 month before surgery (group A), or not (group B). Thirty-eight patients were excluded from further analysis because of a time from embolization of more than 1 month before surgery $(\mathrm{N}=9)$, embolization after surgery $(\mathrm{N}=3)$, or a follow-up time of $<3$ months after surgery in the absence of death $(\mathrm{N}=26)$.

\section{Gene methylation classification}

For methylation analysis, Illumina 450k Human BeadChip (Illumina, San Diego, CA) arrays were employed. Samples were assessed within the discovery cohort of the pivotal study defining methylation subgroups [15].

\section{Pre-operative meningioma embolization}

Tumor embolization was performed under general anesthesia utilizing a $5 \mathrm{~F}$ diagnostic catheter (Cook Medical, Bloomington, IN) for access through the right femoral artery by a modified Seldinger technique. Six-vessel angiography was performed prior to the introduction of a microcatheter for superselective angiographic analysis of the blood supply of the meningioma, followed by polyvinyl alcohol particle (PVA)-based embolization with microparticles measuring 45 to $150 \mu \mathrm{m}$ in diameter (Embozene ${ }^{\circledR}$ Microspheres; Celonova, San Antonio, TX). PVA injection was ceased when stagnation of blood flow in the terminal segment of respective arteries was achieved and all accessible feeder arteries were embolized. Tumor devascularization was confirmed on magnetic resonance imaging (MRI, Figure 1A) or computed tomography (CT) within 48 hours following the endovascular intervention. Enhanced mitotic activity in embolization-induced peri-necrotic tumor portions was not referenced for histopathological grading (Figure 1B).

\section{Variables}


Clinical data were obtained by review of medical reports. Imaging data were reevaluated with a focus on maximal tumor diameter, hemorrhage and absence or presence of edema. Gross total resection (GTR) was defined as the absence of contrast enhancement on post-operative computed tomography (CT) or MRI scans. For safety analyses of the embolization procedure, events were considered related until surgery or for a maximum of 3 months. Adverse neurological outcome was defined as post-operative new onset of neurological symptoms, or as a worsening of neurological symptoms that persisted at least 3 months after surgery. Adverse cardiovascular outcome was defined as any of the following events within 3 months after surgery: pulmonary embolism, deep vein thrombosis, sinus vein thrombosis, ischemic stroke, myocardial infarction, and cardiovascular death or sudden death of unexplained cause. Time to recurrence was defined as the time to re-intervention, including re-resection, radiotherapy or systemic therapies, or death from meningioma progression. Post-operative radiotherapy of residual tumor was not classified as recurrence.

\section{Statistical methods}

The Chi Square test was performed for analyses of nominal and ordinal variables and the MannWhitney-U test was performed for continuous variables. Binary logistic regression was performed for multivariate testing of factors associated with neurological outcome or cardiovascular complications of meningioma surgery and Cox proportional hazards models were applied to determine factors associated with recurrence-free survival.

\section{Results}

\section{Study population}

The study population of 779 patients with histologically confirmed intracranial meningioma was previously characterized in the context of post-operative epilepsy risk [9]. Here, only patients with a minimum post-operative follow-up time of at least 3 months were included in analyses of neurological and cardiovascular outcome $(\mathrm{N}=741)$. This population included 337 patients 
(42.3\%) who underwent pre-operative tumor embolization (group A) and 404 patients (57.7\%)

who did not (group B) (Supplementary Figure 1). The median time to surgery was 2 days and the vast majority of embolized patients underwent embolization within one week prior to surgery (N=308, 91.4\%, Supplementary Figure 2A). During a median follow-up time of 69 months (95\% confidence interval [CI] 64-75), 167 patients (22.5\%) experienced progressive or recurrent disease and 124 patients $(16.7 \%)$ died.

\section{Clinical characteristics of patients with versus without pre-operative tumor embolization}

The clinical characteristics of patients in group A versus group B are summarized in Table 1. Age, gender, tumor location and presence of multiple meningiomas were balanced between both groups. Group A contained more WHO grade II or grade III versus grade I tumors, and of the 9 histological WHO grade I variants, only psammomatous meningiomas were less frequent in group A versus group B (1.0\% versus 3.4\%, $\mathrm{P}=.042)$ (Supplementary Table 1). On imaging scans obtained prior to surgery, meningiomas in group A were larger and more frequently accompanied by peritumoral edema. Within group A, peritumoral edema was detected less frequently after versus before embolization. More detailed analyses of imaging scans in group A versus group B revealed similar rates for hyperostosis, intraosseous growth, extracranial growth or infiltration of venous sinuses in both groups. Yet, group A versus group B was associated with lower rates of calcification $(22.3 \%$ versus $32.2 \%, \mathrm{P}=.003)$ and of radiographic gross total resection $(69.1 \%$ versus $80.3 \%, \mathrm{P}=.001)$, and with higher rates of post-operative brain edema (55.0\% versus $34.8 \%, \mathrm{P}=.006)$ and intraaxial growth $(9.3 \%$ versus $5.5 \%, \mathrm{P}=.052)$ (Supplementary Table 2). Furthermore, Simpson grade 1 resection was achieved at lower rates in embolized patients, the median operation time was $1 \mathrm{~h}$ longer compared to the no embolization group, and embolization was linked to a higher rate of recurrent or progressive tumor growth during follow-up (Table 1), indicating higher surgical complexity of patients selected for preoperative embolization, e.g., due to a smaller fraction of patients with convexity meningiomas and larger tumor size in the embolization group.

\section{Complications from meningioma embolization}


Any patients that underwent embolization for a radiographically suspected intracranial meningioma were included in safety analyses of the embolization procedure, regardless of whether surgery was done subsequently $(\mathrm{N}=358)$. Acute potentially live threatening or disabling complications from embolization occurred in 5 patients $(1.4 \%)$, including stroke $(\mathrm{N}=3)$, intratumoral hemorrhage $(\mathrm{N}=1)$ and serial generalized epileptic seizures $(\mathrm{N}=1)$. Furthermore, two patients suffered mild transient neurological symptoms with gradual onset within 24 hours from embolization and good response to anti-edematous therapy, consisting of hemianopia and aphasia, respectively. One patient with Marfan syndrome suffered an aortic dissection 2 months after the embolization. There was no fatal complication.

Neurological outcome after meningioma resection by embolization status

Adverse neurological events within 3 months after surgery were more frequent in group A versus group B (57.0\% verus $44.8 \%, \mathrm{P}=.001)$. Supplementary Table 3 summarize the most common post-operative neurological events by study group. Rates of trigeminal neuralgia, sensorimotor deficits, visual deficits, early symptomatic seizures, neurocognitive deficits, central nervous system (CNS) infections and recraniotomy were similar in both groups, but cranial nerve palsy, hydrocephalus and intracranial hemorrhage as well as post-operative new onset epilepsy were more frequent in group A. Patients with pre-operative epilepsy were balanced between group A versus group B $(29.2 \%$ versus $35.0 \%, \mathrm{P}=.091)$; however, a smaller fraction of patients with preoperative epilepsy became seizure free after surgery in group A versus group B $(51.7 \%$ versus $64.4 \%, \mathrm{P}=.048)$. We have also analyzed residuals of adverse neurological events 1 year postoperatively. Among 686 patients with a follow-up of at least 1 year, 316 (46.1\%) were in group A and $370(53.9 \%)$ in group B. In group A versus group B, 69 (21.8\%) versus 67 (18.1\%) patients had residuals from adverse neurological events associated with surgery $(\mathrm{P}=.22)$. 
Cardiovascular risk factors were balanced between both groups, including the number of risk factors $(\mathrm{P}=.84)$ and pre-operative cardiovascular events $(\mathrm{P}=.98$, Table 2$)$. Adverse

cardiovascular events after surgery were more frequent in group A versus group B (17.5\% versus $8.2 \%, \mathrm{P}<.001)$. Ischemic stroke, myocardial infarction and sinus vein thrombosis occurred at similar rates in both groups, but patients in group A suffered more deep vein thromboses and pulmonary embolisms, and group A was associated with a higher rate of death (Supplementary Table 3). Post-operative hematological parameters did not differ in group A versus group B, except for slightly lower median values for platelet counts $(\mathrm{P}=.002)$ and hematocrit $(\mathrm{P}<.001)$ (Supplementary Table 4).

\section{Multivariate and subgroup analyses}

We applied a binary logistic regression model controlling for demographics, WHO grade and imaging characteristics to test whether pre-operative tumor embolization is a predictor of cardiovascular outcome (Table 3). Univariate analyses of the association of variables included in this model are summarized in Supplementary Table 5. An association with higher cardiovascular risk was identified for group A (odds ratio [OR] 2.38, 95\% CI 1.37-4.00, P = .002) and female gender (OR 2.18, 95\% CI 1.17-4.08, P =.014). No association was identified for age, WHO grade, tumor size, presence of multiple meningiomas, radiographic extent of resection or cardiovascular risk factors. Factors that were tested as additional single variables in this model are summarized in Supplementary Table 6: Tumor location at the skull base (OR 2.33, 95\% CI $1.40-3.86, \mathrm{P}=.001)$ and adverse neurological outcome (OR 1.75, 95\% CI 1.05-2.86, $\mathrm{P}=.032)$ were associated with inferior cardiovascular outcome. In reverse, parasagittal tumor location (OR $0.44,95 \%$ CI $0.20-0.98, \mathrm{P}=.045)$ and thrombocyte levels of 220/nl or higher on post-operative blood cell counts (OR 0.55, 95\% CI 0.29-1.05, P =.069) correlated with lower cardiovascular risk. No association was identified for the presence or absence of pre-operative neurological deficits $(\mathrm{P}=.43)$, pre-operative brain edema $(\mathrm{P}=.93)$, post-operative brain edema $(\mathrm{P}=.64)$, duration of surgery $(\mathrm{P}=.31)$ tumor calcification $(\mathrm{P}=.47)$, post-operative epilepsy $(\mathrm{P}=.26)$, intraaxial growth $(\mathrm{P}=.37)$, or post-operative hematocrit levels $(\mathrm{P}=.40)$ (Supplementary Table 6). Group A was associated with inferior cardiovascular outcome in most subgroups, but not in male patients, patients with multiple meningiomas or patients with posterior fossa meningiomas 
(Supplementary Figure 3). Among embolized patients, a time to surgery of one week or less versus longer intervals were not associated with cardiovascular outcome (OR 0.61, 95\% CI 0.231.63, $\mathrm{p}=0.32$ ), and applying receiver operator characteristics (ROC) curve analyses to cardiovascular outcome identified no predictive cut-off for the time interval between embolization and surgery (sensitivity 58\%, specificity 46\%, Supplementary Figure 2B). Similar analyses evaluating risk factors for adverse neurological outcome 3 months after surgery were also performed and similarly identified associations with embolization (OR 1.85, 95\% CI $1.30-2.63, \mathrm{P}=.001)$, whereas radiographic gross total resection was associated with better neurological outcome (OR 0.59, 95\% CI 0.39-0.87, $\mathrm{P}=.006)$, with no significant interaction between both predictors $(\mathrm{P}=.17)$. Further details are summarized in Supplementary Tables 7 and 8, and Supplementary Figure 3.

\section{Recurrence-free survival by embolization status}

Tumor recurrence during the entire follow-up period was documented in 167 patients, including 87 of 337 patients $(25.8 \%)$ in group $\mathrm{A}$ and 80 of 404 patients $(19.8 \%)$ in group $\mathrm{B}(\mathrm{P}=.052)$. The median recurrence-free survival (RFS) was 12 years in patients with embolization and not reached in patients without embolization $(\mathrm{P}=.043)$. Multivariate analyses applying a Cox proportional hazards model of shorter RFS that controlled for the established prognostic factors outlined in Table 3 rendered WHO grade II or grade III versus grade I the strongest factor associated with shorter RFS (HR 3.83, 95\% CI 2.30-6.37, P <.001). Therefore, we also performed analyses segregated by WHO grade.

The RFS in group A versus group B did not differ in patients with WHO grade I meningiomas (P $=.89$, Figure 2A). Among patients with WHO grade II or grade III meningiomas, the RFS was 4.3 years in group A versus 7.0 years in group $\mathrm{B}(\mathrm{P}=.029$, Figure $2 \mathrm{~B})$ and outcome with respect to RFS was less favorable in group A versus group B in a similar Cox model (HR 1.92, 95\% CI 0.97-3.79, $\mathrm{P}=.062)$.

Molecular tumor characteristics may predict the clinical course more accurately than histology alone, and such approaches to re-classify meningiomas include genome-wide methylation signatures that are more closely associated with recurrence than histological WHO grading [15]. Gene methylation-based classification of prognostic molecular subtypes was available from 81 
patients, including 41 patients assigned to the benign subtype and 40 patients with an intermediate $(\mathrm{N}=35)$ or malignant $(\mathrm{N}=5)$ gene methylation pattern. Paralleling the prognostic role of WHO grading, an intermediate or malignant versus benign gene methylation pattern was the strongest factor associated with shorter time to re-intervention when replacing WHO grade in the Cox model utilizing the variables outlined in Table 3 (HR 8.66, 95\% CI 3.00-25.05, P <.001). The RFS in group A versus group B did not differ in patients with benign subtype meningiomas $(\mathrm{P}=.11$, Figure $2 \mathrm{C})$. Among patients with intermediate or malignant subtype meningiomas, the time to re-intervention was 2.0 years in group A versus 8.2 years in group $B(P=.005$, Figure 2D) and outcome was less favorable in group A versus group B in a similar Cox model (HR 4.08, 95\% CI 0.91-18.21, $\mathrm{P}=.066)$.

\section{Discussion}

Here we have analyzed the post-operative outcomes of 741 consecutive patients with histologically diagnosed meningioma, including 337 patients that underwent pre-operative tumor embolization versus 404 patients who did not undergo embolization. Moreover, molecular meningioma subtypes with better prognostic accuracy compared to histological WHO grading [15] were defined by genome-wide methylation arrays in 81 patients.

Outcome parameters after surgery included the likelihood of adverse cardiovascular events within 3 months, persistence of neurological deficits with peri-operative new onset at 3 months and at 1 year after surgery, and recurrence-free survival as defined by the time to re-intervention or tumorrelated death as a clinically relevant indicator. Multivariate analyses controlling for established prognosticators of outcome after meningioma surgery identified pre-operative embolization as an important risk factor for post-operative cardiovascular adverse events. Embolization was also associated with a higher rate of neurological adverse events after surgery, but no difference in the rate of neurological deficits 1 year after surgery. Recurrence-free survival was less favorable with embolization in patients with WHO grade II or grade III meningiomas, and with intermediate or

malignant gene methylation patterns, but not in patients with WHO grade I or benign methylation subtype meningiomas.

Prospective studies of the effects of embolization in meningioma patients are scarce [16] and mostly restricted to small series without comparator groups [5]. Previous reports of retrospective 
cohorts focused on intraoperative blood loss, complication rates and comparison of these parameters with the use of different embolization materials [17-22]. Reports on associations of embolization with post-operative neurological outcomes are limited, with associations of embolization with cardiovascular adverse events or tumor recurrence not previously reported. To date, two recent studies explored associations of post-operative cardiovascular risk in meningioma patients [12,11]. In contrast to these studies, we did not detect associations of duration of surgery, older age and comorbidities with cardiovascular risk on multivariate analyses. Similar to previous reports, adverse neurological outcome was associated with cardiovascular risk and there was a previously not reported strong association of female gender. In our cohort, procedure-related complications from embolization occurred at low rates compared to previous studies [23], indicating a high level of experience of the interventional neuroradiologists. The use of PVA for embolization in all patients of our cohort and uniform standards of post-operative prophylaxis of thromboembolism [24] may have prevented confounding of the data by heterogeneous algorithms of care.

Limitations of our study include the retrospective design and imbalances of key prognostic factors, albeit these were not prognostic on multivariate and subgroup analyses. The lack of an independent neuropathology review furthermore retains the possibility that the larger fraction of WHO grade II and grade III meningiomas among embolized patients were caused by misinterpretation of histological changes induced by the embolization procedure $[7,8]$. Yet, the shorter RFS with embolization among patients with WHO grade II or grade III meningiomas was confirmed utilizing an observer-independent molecular classification approach [15], which was more powerful in detecting survival differences than histological classification.

Reasons for the shorter RFS with embolization are elusive, but the induction of mitotic activity that is commonly observed around necrotic tumor fractions after embolization may have contributed to accelerated tumor growth. Furthermore, larger tumor size and edema on preoperative imaging scans were associated with the decision to perform embolization. These indicators of less favorable disease courses and of more challenging surgery were reflected by a longer duration of surgery and have likely contributed to the higher rate of neurological deficits and shorter RFS in embolized patients, albeit embolization was identified as the most relevant prognostic factor on multivariate models of neurological outcome and RFS. Moreover, the extent of devascularization achieved, or changes on diffusion weighted images are additional factors that may have been associated with outcome, but such data were not available. Compared to 
clinical practice in most centers, the rate of embolization in our cohort was relatively high, thus potentially limiting the generalizability of our results. The high rate of embolization results from Zurich being a referral center over many years and potentially a bias towards offering this intervention to patients rather frequently. There certainly was a belief in benefit from embolization because of reducing bleeding risk.

The reasons for the higher rate of cardiovascular events remain elusive. In consideration of the lack of an association with the cardiovascular risk profile of patients or with hematological parameters, we speculate that systemic factors released from necrotic tissue after embolization may have contributed to higher rates of thromboembolism in patients undergoing meningioma embolization. However, other factors that have not been assessed may have confounded our analyses, including steroid use or immobilization time after surgery.

In conclusion, the adverse outcomes with embolization reported here emphasize the necessity of randomized trials to determine when the benefit outweighs the risk of pre-operative meningioma embolization and which patients may potentially benefit. Future prospective studies should include standardized assessments of the extent of devascularization and other clinically relevant outcome parameters beyond estimated blood loss, such as health-related quality of life, disability scores and neurological functioning.

Funding: There was no funding for this study.

Conflict of Interest: The authors declare that they have no conflict of interest.

Ethical approval: All procedures performed in studies involving human participants were in accordance with the ethical standards of the regional research committee and with the 1964 Helsinki declaration and its later amendments or comparable ethical standards. For this type of study formal consent is not required.

\section{References}

1. Ostrom QT, Gittleman H, Fulop J, Liu M, Blanda R, Kromer C, Wolinsky Y, Kruchko C, Barnholtz-Sloan JS (2015) CBTRUS Statistical Report: Primary Brain and Central Nervous System Tumors Diagnosed in the United States in 2008-2012. Neuro Oncol 17 Suppl 4:iv1-iv62. doi:10.1093/neuonc/nov189 
2. Louis DN, Perry A, Reifenberger G, von Deimling A, Figarella-Branger D, Cavenee WK, Ohgaki H, Wiestler OD, Kleihues P, Ellison DW (2016) The 2016 World Health Organization classification of tumors of the central nervous system: a summary. Acta Neuropathol 131 (6):803-820. doi:10.1007/s00401-016-1545-1

3. Goldbrunner R, Minniti G, Preusser M, Jenkinson MD, Sallabanda K, Houdart E, von Deimling A, Stavrinou P, Lefranc F, Lund-Johansen M, Moyal EC, Brandsma D, Henriksson R, Soffietti R, Weller M (2016) EANO guidelines for the diagnosis and treatment of meningiomas. Lancet Oncol 17 (9):e383-391. doi:10.1016/s1470-2045(16)30321-7

4. Rogers L, Barani I, Chamberlain M, Kaley TJ, McDermott M, Raizer J, Schiff D, Weber DC, Wen PY, Vogelbaum MA (2015) Meningiomas: knowledge base, treatment outcomes, and uncertainties. A RANO review. J Neurosurg 122 (1):4-23. doi:10.3171/2014.7.JNS131644

5. Shah AH, Patel N, Raper DM, Bregy A, Ashour R, Elhammady MS, Aziz-Sultan MA, Morcos JJ, Heros RC, Komotar RJ (2013) The role of preoperative embolization for intracranial meningiomas. J Neurosurg 119 (2):364-372. doi:10.3171/2013.3.jns121328

6. Singla A, Deshaies EM, Melnyk V, Toshkezi G, Swarnkar A, Choi H, Chin LS (2013) Controversies in the role of preoperative embolization in meningioma management. Neurosurg Focus 35 (6):E17. doi:10.3171/2013.9.FOCUS13351

7. Perry A, Chicoine MR, Filiput E, Miller JP, Cross DT (2001) Clinicopathologic assessment and grading of embolized meningiomas: a correlative study of 64 patients. Cancer 92 (3):701-711

8. Barresi V, Branca G, Granata F, Alafaci C, Caffo M, Tuccari G (2013) Embolized meningiomas: risk of overgrading and neo-angiogenesis. J Neurooncol 113 (2):207-219. doi:10.1007/s11060-013-1117-3

9. Wirsching HG, Morel C, Gmur C, Neidert MC, Baumann CR, Valavanis A, Rushing EJ, Krayenbuhl N, Weller M (2016) Predicting outcome of epilepsy after meningioma resection. Neuro Oncol 18 (7):1002-1010. doi:10.1093/neuonc/nov303

10. Sanai N, Sughrue ME, Shangari G, Chung K, Berger MS, McDermott MW (2010) Risk profile associated with convexity meningioma resection in the modern neurosurgical era. $\mathbf{J}$ Neurosurg 112 (5):913-919. doi:10.3171/2009.6.JNS081490 
11. Carrabba G, Riva M, Conte V, Di Cristofori A, Caroli M, Locatelli M, Castellani M, Bucciarelli P, Artoni A, Stocchetti N, Martinelli I, Rampini P (2018) Risk of post-operative venous thromboembolism in patients with meningioma. J Neurooncol 138 (2):401-406. doi:10.1007/s11060-018-2810-z

12. Karhade AV, Fandino L, Gupta S, Cote DJ, Iorgulescu JB, Broekman ML, Aglio LS, Dunn IF, Smith TR (2017) Impact of operative length on post-operative complications in meningioma surgery: a NSQIP analysis. J Neurooncol 131 (1):59-67. doi:10.1007/s11060-016-2262-2 13. Hoefnagel D, Kwee LE, van Putten EH, Kros JM, Dirven CM, Dammers R (2014) The incidence of postoperative thromboembolic complications following surgical resection of intracranial meningioma. A retrospective study of a large single center patient cohort. Clin Neurol Neurosurg 123:150-154. doi:10.1016/j.clineuro.2014.06.001

14. Levi AD, Wallace MC, Bernstein M, Walters BC (1991) Venous thromboembolism after brain tumor surgery: a retrospective review. Neurosurgery 28 (6):859-863

15. Sahm F, Schrimpf D, Stichel D, Jones DT, Hielscher T, Schefzyk S, Okonechnikov K, Koelsche C, Reuss DE, Capper D, Sturm D, Wirsching HG, Berghoff AS, Baumgarten P, Kratz A, Huang K, Wefers AK, Hovestadt V, Sill M, Ellis HP, Kurian KM, Okuducu AF, Jungk C, Drueschler K, Schick M, Bewerunge-Hudler M, Mawrin C, Seiz-Rosenhagen M, Ketter R, Simon M, Westphal M, Lamszus K, Becker A, Koch A, Schittenhelm J, Rushing EJ, Collins VP, Brehmer S, Chavez L, Platten M, Hanggi D, Unterberg A, Paulus W, Wick W, Pfister SM, Mittelbronn M, Preusser M, Herold-Mende C, Weller M, von Deimling A (2017) DNA methylation-based classification and grading system for meningioma: a multicentre, retrospective analysis. Lancet Oncol. doi:10.1016/S1470-2045(17)30155-9

16. Bendszus M, Rao G, Burger R, Schaller C, Scheinemann K, Warmuth-Metz M, Hofmann E, Schramm J, Roosen K, Solymosi L (2000) Is there a benefit of preoperative meningioma embolization? Neurosurgery 47 (6):1306-1311; discussion 1311-1302

17. Bendszus M, Monoranu CM, Schutz A, Nolte I, Vince GH, Solymosi L (2005) Neurologic complications after particle embolization of intracranial meningiomas. Am J Neuroradiol 26 (6):1413-1419 
18. Nguyen H, Janich K, Doan N, Patel M, Li L, Mueller W (2017) Extent of T1+C Intensity is a Predictor of Blood Loss in Resection of Meningioma. World Neurosurg. doi:10.1016/j.wneu.2017.01.098

19. Borg A, Ekanayake J, Mair R, Smedley T, Brew S, Kitchen N, Samandouras G, Robertson F (2013) Preoperative Particle and Glue Embolization of Meningiomas: Indications, Results and Lessons Learned from 117 Consecutive Patients. Neurosurgery. doi:10.1227/NEU.0b013e31828e1ffd

20. Chun JY, McDermott MW, Lamborn KR, Wilson CB, Higashida R, Berger MS (2002) Delayed surgical resection reduces intraoperative blood loss for embolized meningiomas. Neurosurgery 50 (6):1231-1235; discussion 1235-1237

21. Fang QR, He XY, Li XF, Zhang X, Chen M, Li H, Li W, Wang ZQ, Duan CZ (2016) Comparative efficacy of Glubran and polyvinyl-alcohol particles in the embolization of meningiomas. Int J Neurosci 126 (12):1112-1119. doi:10.3109/00207454.2015.1134525

22. Raper DM, Starke RM, Henderson F, Jr., Ding D, Simon S, Evans AJ, Jane JA, Sr., Liu KC (2014) Preoperative embolization of intracranial meningiomas: efficacy, technical considerations, and complications. Am J Neuroradiol 35 (9):1798-1804. doi:10.3174/ajnr.A3919

23. Shah A, Choudhri O, Jung H, Li G (2015) Preoperative endovascular embolization of meningiomas: update on therapeutic options. Neurosurg Focus 38 (3):E7. doi:10.3171/2014.12.FOCUS14728

24. Eisenring CV, Neidert MC, Sabanes Bove D, Held L, Sarnthein J, Krayenbuhl N (2013) Reduction of thromboembolic events in meningioma surgery: a cohort study of 724 consecutive patients. PLoS One 8 (11):e79170. doi:10.1371/journal.pone.0079170 


\section{Figure legends}

Figure 1. Imaging and histopathological effects of meningioma embolization. $A$, MRI and angiography of the internal carotid artery before and after embolization of a parasagittal meningioma. Contrast enhancement was assessed on T1-weighted sequences. FLAIR, fluid attenuated inversion recovery. $B$, Histopathological stainings of $(i)$ a non-embolized portion of a transitional meningioma (WHO grade I, hematoxylin and eosin stain [H\&E]), (ii) embolization material (PVA particles 45-150 $\mu \mathrm{m}$ ) in a meningioma feeder artery (H\&E), (iii) embolizationinduced necrosis and micro-bleeds (H\&E) and (iv) peri-necrotic proliferation, Ki-67 immunohistochemistry stain. Scale bar: $100 \mu \mathrm{m}$.

Figure 2. Recurrence-free survival in patients with pre-operative embolization (group A) versus without embolization (group B). $A$, WHO grade I (N=606); $B$ WHO grade II (N=114) or grade III $(\mathrm{N}=21) ; C$, benign (ben) gene methylation subtype $(\mathrm{N}=41) ; D$, intermediate $(\mathrm{N}=36)$ or malignant $(\mathrm{N}=5)$ gene methylation subtype. The log rank test was applied to assess differences in time to reintervention.

\section{Supplementary Data}

Supplementary Figure 1. Study population.

Supplementary Figure 2. Timing of embolization. A, Frequency distribution of the time between embolization and surgery. $B$, ROC curve analysis of timing of embolization utilizing cardiovascular events as the outcome.

Supplementary Figure 3. Subgroup analyses. Indicated subgroups were analyzed for an association of pre-operative tumor embolization with inferior neurological outcome at 3 months after surgery or cardiovascular events within 3 months after surgery in the multivariate binary regression model outlined in Table 3.

Supplementary Table 1. Histological subtypes of patients with versus without embolization. 
Supplementary Table 2. Imaging characteristics of patients with versus without embolization.

Supplementary Table 3. Adverse neurological and cardiovascular events 3 months after meningioma resection in patients with versus without pre-operative embolization.

Supplementary Table 4. Post-operative hematological parameters of patients with versus without pre-operative embolization.

Supplementary Table 5. Univariate analyses of variables tested in the multivariate models outlined in Table 3.

Supplementary Table 6. Additional single variables tested in the multivariate model outlined in Table 3.

Supplementary Table 7. Multivariate analyses of predictors for adverse neurological outcome 3 months after meningioma resection.

Supplementary Table 8 . Additional single variables tested in the multivariate model outlined in Supplementary Table 7. 


\section{Figure 1}

A
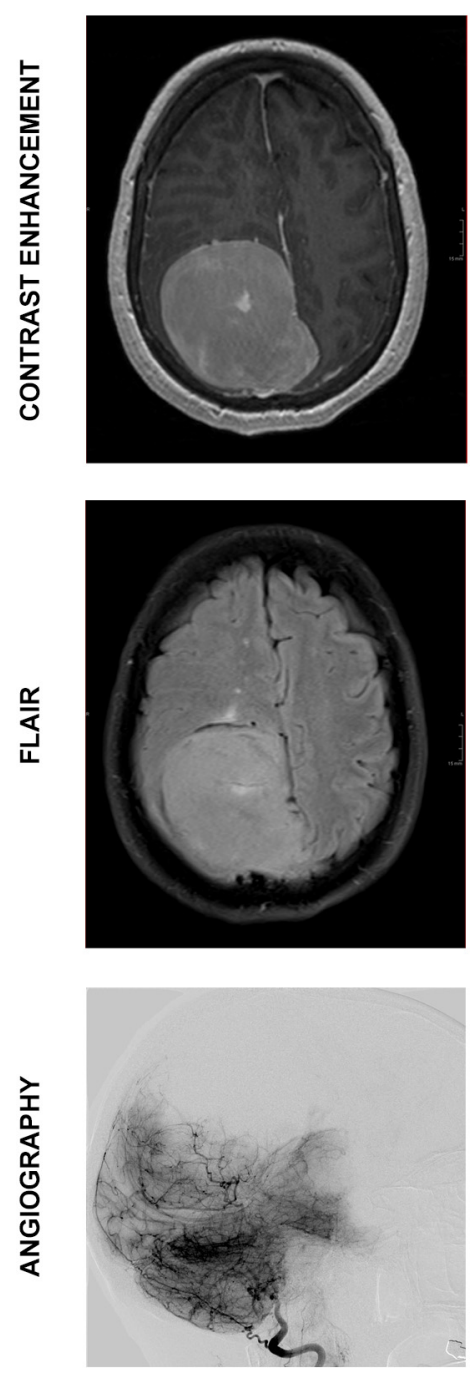

AFTER EMBOLIZATION
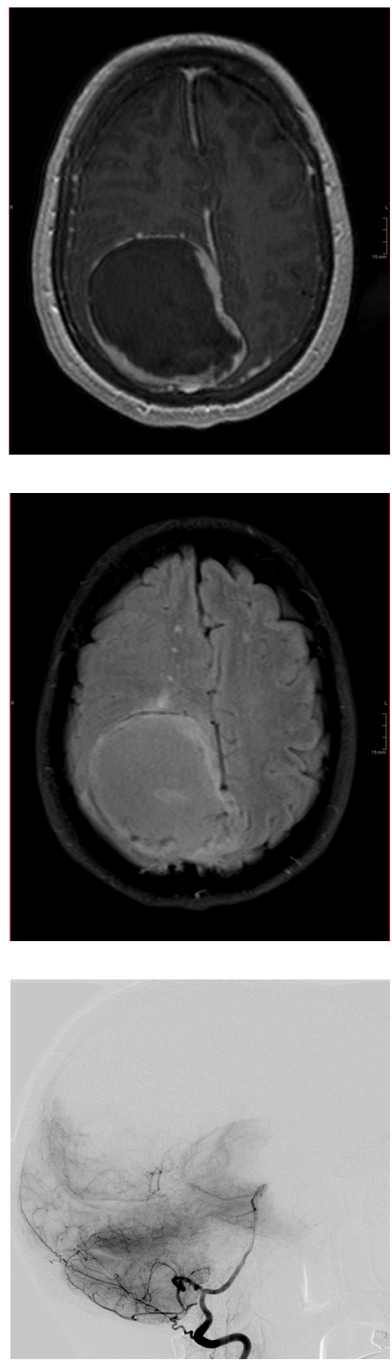

B
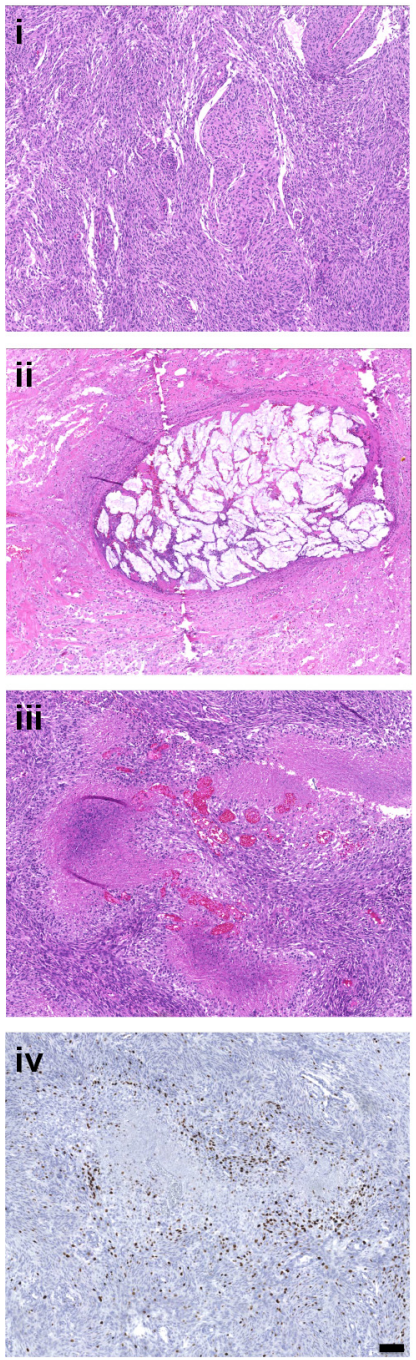


\section{Supplementary data}

Journal of Neuro-Oncology

Post-operative cardiovascular complications and time to recurrence in meningioma patients treated with versus without pre-operative embolization: a retrospective cohort study of 741 patients

Hans-Georg Wirsching, MD, ${ }^{1,}$ Johannes Konstantin Richter, MD, ${ }^{2}$ Felix Sahm, MD, Corinne Morel, MD, ${ }^{1}$ Niklaus Krayenbuehl, MD, ${ }^{3}$ Elisabeth Jane Rushing, MD, ${ }^{4}$ Andreas von Deimling, MD, ${ }^{5}$ Antonios Valavanis, MD, ${ }^{2}$ Michael Weller, MD, ${ }^{1}$

Departments of ${ }^{1}$ Neurology, ${ }^{2}$ Neuroradiology, ${ }^{3}$ Neurosurgery and ${ }^{4}$ Neuropathology, University Hospital and University of Zurich, Zurich, Switzerland; ${ }^{5}$ Department of Neuropathology, University Hospital Heidelberg and Clinical Cooperation Unit Neuropathology, German Consortium for Translational Cancer Research (DKTK), German Cancer Research Center (DKFZ), Heidelberg, Germany.

* Corresponding author: Hans-Georg Wirsching, MD, Department of Neurology, University Hospital Zurich and University of Zurich, Zurich, Frauenklinikstrasse 26, 8091 Zurich, Switzerland, Phone: +41-44-255-5500, Fax: +41-44-255-4507, E-mail: hans-georg.wirsching@usz.ch 


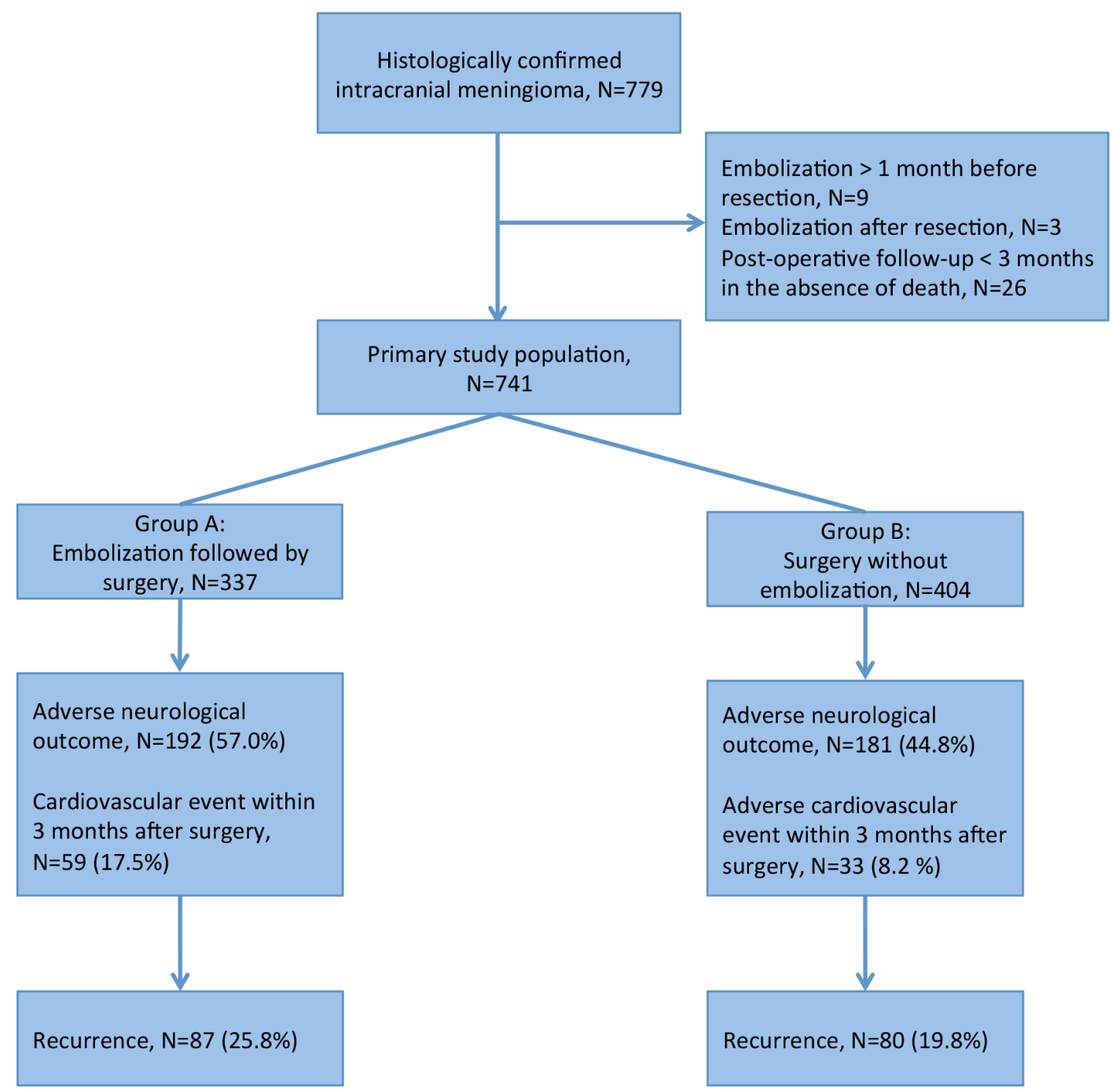

Supplementary Figure 1. Study population. 
A

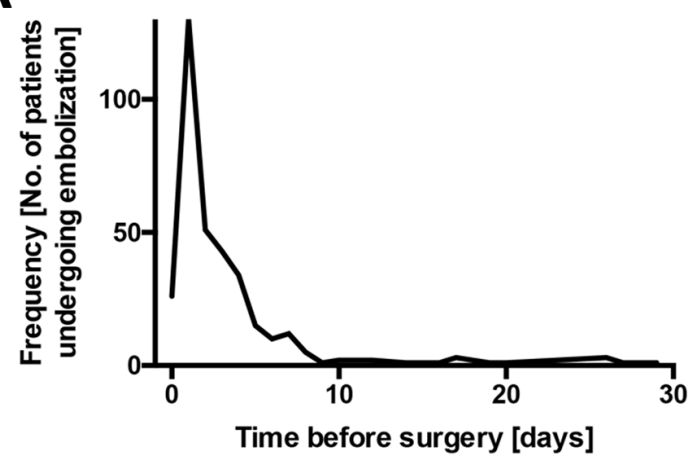

B

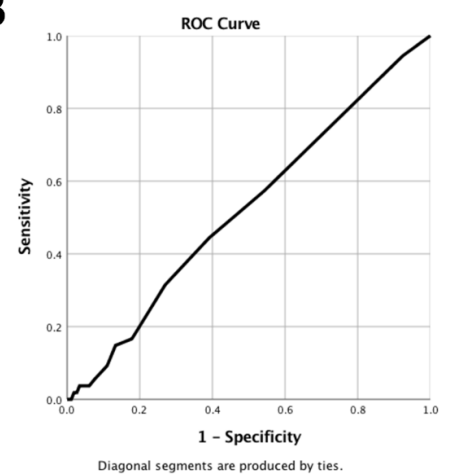

Supplementary Figure 2. Timing of embolization. A, Frequency distribution of the time between embolization and surgery. B, ROC curve analysis of timing of embolization utilizing cardiovascular events as the outcome. 

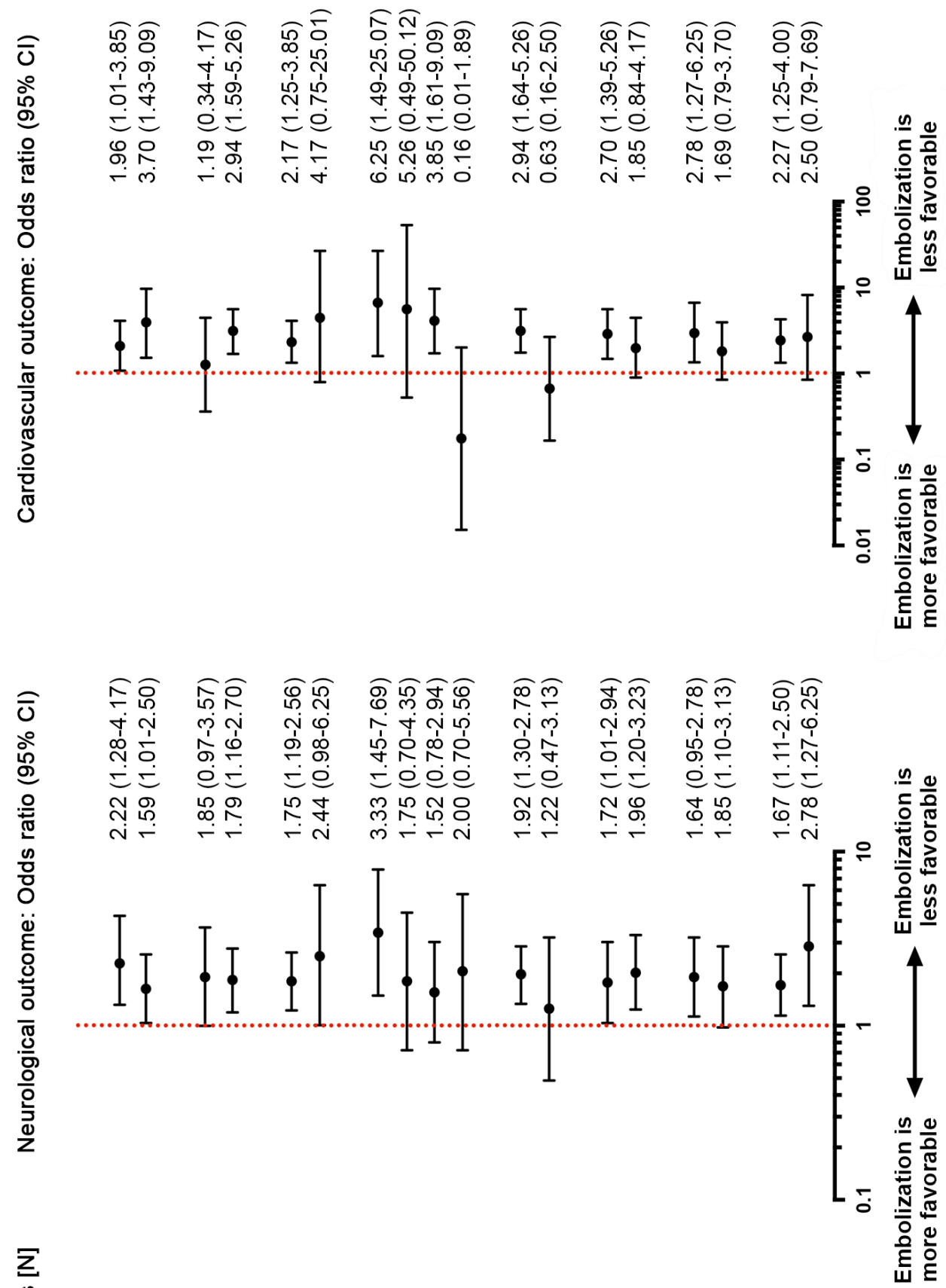

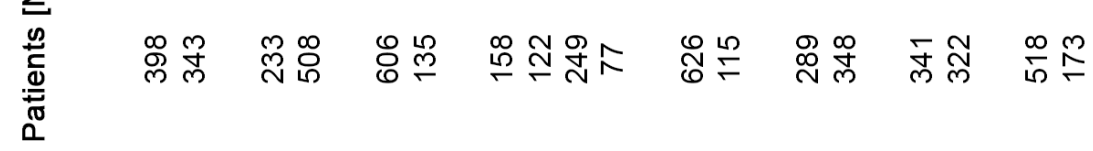

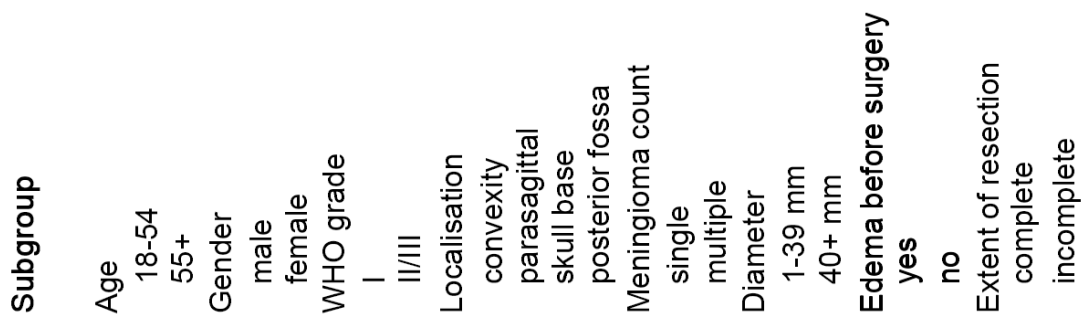

Supplementary Figure 3. Subgroup analyses. Indicated subgroups were analyzed for an association of pre-operative tumor embolization with inferior neurological outcome at 3 months after surgery or cardiovascular events within 3 months after surgery in the multivariate binary regression model outlined in Table 3. 
Supplementary Table 1. Histological subtypes of patients with versus without embolization ${ }^{a}$.

\begin{tabular}{|c|c|c|c|}
\hline & \multicolumn{2}{|c|}{ Embolization } & \multirow[b]{2}{*}{$\mathrm{P}$} \\
\hline & $\begin{array}{c}\text { Yes (group A) } \\
\mathrm{N}=304(48.3 \%)\end{array}$ & $\begin{array}{c}\text { No (group B) } \\
\mathrm{N}=325(51.7 \%)\end{array}$ & \\
\hline \multicolumn{4}{|l|}{ WHO grade I: N (\%) } \\
\hline Meningothelial & $130(42.8)$ & $154(47.4)$ & .24 \\
\hline Fibrous & $33(10.9)$ & $34(10.5)$ & .87 \\
\hline Transitional & $49(16.1)$ & $58(17.8)$ & .56 \\
\hline Psammomatous & $3(1.0)$ & $11(3.4)$ & .042 \\
\hline Angiomatous & $7(2.3)$ & $10(3.1)$ & .55 \\
\hline Microcystic & $2(0.7)$ & $4(1.2)$ & $.69 *$ \\
\hline Secretory & $9(3.0)$ & $6(1.8)$ & $.44^{*}$ \\
\hline Lymphoplasmacyte-rich & - & $2(0.6)$ & n.a. \\
\hline Metaplastic & - & $1(0.3)$ & n.a. \\
\hline \multicolumn{4}{|l|}{ WHO grade II: N (\%) } \\
\hline Atypical & $53(17.4)$ & $36(11.1)$ & .022 \\
\hline Clear cell & $1(0.3)$ & - & n.a. \\
\hline Chordoid & $1(0.3)$ & $4(1.2)$ & $.37 *$ \\
\hline \multicolumn{4}{|l|}{ WHO grade III: N (\%) } \\
\hline Rhabdoid & $1(0.3)$ & - & n.a. \\
\hline Papillary & $2(0.7)$ & - & n.a. \\
\hline Anaplastic & $13(4.3)$ & $5(1.5)$ & $.054^{*}$ \\
\hline
\end{tabular}

${ }^{\text {a }} \mathrm{N}=629$ patients with detailed histopathologic reports available; * Fisher's exact test, 2-sided 
Supplementary Table 2. Imaging characteristics of patients with versus without embolization.

\begin{tabular}{|c|c|c|c|}
\hline & \multicolumn{2}{|c|}{ Embolization } & \multirow{3}{*}{$\mathrm{P}$} \\
\hline & Yes (group A) & No (group B) & \\
\hline & $\mathrm{N}=332(46.7 \%)$ & $\mathrm{N}=379(53.3 \%)$ & \\
\hline \multicolumn{4}{|l|}{ Calcification: N (\%) } \\
\hline Yes & $74(22.3)$ & $122(32.2)$ & \multirow{2}{*}{.003} \\
\hline No & $258(77.7)$ & $257(67.8)$ & \\
\hline \multicolumn{4}{|l|}{ Hyperostosis: N (\%) } \\
\hline Yes & $102(30.7)$ & $99(26.1)$ & \multirow{2}{*}{.17} \\
\hline No & $230(69.3)$ & $280(73.9)$ & \\
\hline \multicolumn{4}{|l|}{$\begin{array}{l}\text { Intraosseus growth: } N \\
(\%)\end{array}$} \\
\hline Yes & $19(5.7)$ & $15(4.0)$ & \multirow{2}{*}{.27} \\
\hline No & $313(94.3)$ & $364(96.0)$ & \\
\hline \multicolumn{4}{|l|}{$\begin{array}{l}\text { Extracranial growth: } \\
\text { N (\%) }\end{array}$} \\
\hline Yes & $24(7.2)$ & $19(5.0)$ & \multirow{2}{*}{.22} \\
\hline No & $308(92.8)$ & $360(95.0)$ & \\
\hline \multicolumn{4}{|l|}{$\begin{array}{l}\text { Intraaxial growth: } \mathrm{N} \\
(\%)\end{array}$} \\
\hline Yes & $31(9.3)$ & $21(5.5)$ & \multirow{2}{*}{.052} \\
\hline No & $301(90.7)$ & $358(94.5)$ & \\
\hline \multicolumn{4}{|l|}{$\begin{array}{l}\text { Infiltration of venous } \\
\text { sinus: } \mathbf{N}(\%)\end{array}$} \\
\hline Yes & $39(11.7)$ & $34(9.0)$ & \multirow{2}{*}{.22} \\
\hline No & $293(88.2)$ & $345(91.0)$ & \\
\hline \multicolumn{4}{|l|}{$\begin{array}{l}\text { Radiographic EOR }{ }^{\mathrm{a}} \text { : } \\
\text { N }(\%)\end{array}$} \\
\hline Gross total resection & $221(69.1)$ & $298(80.3)$ & \multirow{2}{*}{.001} \\
\hline Incomplete resection & $99(30.9)$ & $73(19.7)$ & \\
\hline
\end{tabular}




\begin{tabular}{|l|l|l|l|}
\hline $\begin{array}{l}\text { Post-operative } \\
\text { edema }^{\text {b }} \text { : N (\%) }\end{array}$ & & & \\
\hline Yes & $149(45.0)$ & $127(34.8)$ & .006 \\
No & $182(55.0)$ & $238(65.2)$ & \\
\hline
\end{tabular}

${ }^{\mathrm{a}} \mathrm{EOR}=$ extent of resection; documentation available in $\mathrm{N}=691$ patients; ${ }^{\mathrm{b}}$ documentation available in $\mathrm{N}=696$ patients 
Supplementary Table 3. Adverse neurological and cardiovascular events 3 months after meningioma resection in patients with versus without pre-operative embolization.

\begin{tabular}{|c|c|c|c|}
\hline & \multicolumn{2}{|c|}{ Embolization } & \multirow{3}{*}{$\mathrm{P}$} \\
\hline & Yes (group A) & No (group B) & \\
\hline & $\mathrm{N}=337(42.3 \%)$ & $\mathrm{N}=404(57.7 \%)$ & \\
\hline \multicolumn{4}{|l|}{ Neurological events ${ }^{a}$} \\
\hline \multicolumn{4}{|l|}{ Cranial nerve palsy: $\mathbf{N}(\%)$} \\
\hline Yes & $47(13.9)$ & $31(7.7)$ & \multirow{2}{*}{.006} \\
\hline No & $290(86.1)$ & $373(92.3)$ & \\
\hline \multicolumn{4}{|l|}{ Trigeminal neuralgia: N (\%) } \\
\hline Yes & $5(1.5)$ & $4(1.0)$ & \multirow{2}{*}{.54} \\
\hline No & $332(98.5)$ & $400(99.0)$ & \\
\hline \multicolumn{4}{|l|}{ Sensorimotor deficit: N (\%) } \\
\hline Yes & $51(15.1)$ & $51(12.6)$ & \multirow{2}{*}{.32} \\
\hline No & $286(84.9)$ & $353(87.4)$ & \\
\hline \multicolumn{4}{|l|}{ Visual deficit: N (\%) } \\
\hline Yes & $27(8.0)$ & $32(7.9)$ & \multirow{2}{*}{.96} \\
\hline No & $310(92.0)$ & $372(92.1)$ & \\
\hline \multicolumn{4}{|l|}{ Epilepsy: N (\%) } \\
\hline $\begin{array}{l}\text { Post-operative new onset } \\
\text { epilepsy }^{\text {b }}\end{array}$ & $52(23.7)$ & $48(16.8)$ & .052 \\
\hline $\begin{array}{l}\text { Seizures within } 1 \text { week from } \\
\text { surgery }\end{array}$ & $20(5.9)$ & $25(6.2)$ & .89 \\
\hline \multicolumn{4}{|l|}{ Neurocognitive deficits: $\mathbf{N}(\%)$} \\
\hline Yes & $29(8.6)$ & $38(9.4)$ & \multirow{2}{*}{.71} \\
\hline No & $308(91.4)$ & $366(90.6)$ & \\
\hline \multicolumn{4}{|l|}{ CNS infection: N (\%) } \\
\hline Yes & $7(2.1)$ & $6(1.5)$ & \multirow{2}{*}{.54} \\
\hline No & $330(97.9)$ & $398(98.5)$ & \\
\hline Hydrocephalus: N (\%) & & & \\
\hline
\end{tabular}




\begin{tabular}{|c|c|c|c|}
\hline $\begin{array}{l}\text { Yes } \\
\text { No }\end{array}$ & $\begin{array}{c}17(5.0) \\
320(95.0)\end{array}$ & $\begin{array}{c}9(2.2) \\
395(97.8)\end{array}$ & .038 \\
\hline \multicolumn{4}{|c|}{ Hemorrhage: N (\%) } \\
\hline $\begin{array}{l}\text { Yes } \\
\text { No }\end{array}$ & $\begin{array}{l}109(32.3) \\
228(67.7)\end{array}$ & $\begin{array}{c}97(24.0) \\
307(76.0)\end{array}$ & .012 \\
\hline \multicolumn{4}{|c|}{ Clinically symptomatic } \\
\hline $\begin{array}{l}\text { Yes } \\
\text { No }\end{array}$ & $\begin{array}{c}57(16.9) \\
280(83.1)\end{array}$ & $\begin{array}{c}32(7.9) \\
372(92.1)\end{array}$ & $<.001$ \\
\hline \multicolumn{4}{|c|}{ Re-craniotomy: N (\%) } \\
\hline $\begin{array}{l}\text { Yes } \\
\text { No }\end{array}$ & $\begin{array}{c}20(5.9) \\
317(94.1)\end{array}$ & $\begin{array}{c}15(3.7) \\
389(96.3)\end{array}$ & .16 \\
\hline \multicolumn{4}{|c|}{ Cardiovascular events } \\
\hline \multicolumn{4}{|c|}{ Ischemic stroke: N (\%) } \\
\hline Yes & $16(4.7)$ & $13(3.2)$ & \multirow{2}{*}{.29} \\
\hline No & $321(95.3)$ & $391(96.8)$ & \\
\hline \multicolumn{4}{|c|}{ Myocardial infarction: $\mathbf{N}(\%)$} \\
\hline Yes & $0(0.0)$ & $2(0.5)$ & \multirow{2}{*}{$.50^{*}$} \\
\hline No & $337(100.0)$ & $402(99.5)$ & \\
\hline \multicolumn{4}{|c|}{ Sinus vein thrombosis: $\mathbf{N}(\%)$} \\
\hline Yes & $5(1.5)$ & $5(1.2)$ & \multirow{2}{*}{$1.000^{*}$} \\
\hline No & $332(98.5)$ & $399(98.8)$ & \\
\hline \multicolumn{4}{|c|}{ Deep vein thrombosis: $\mathbf{N}(\%)$} \\
\hline Yes & $24(7.1)$ & $15(3.7)$ & \multirow{2}{*}{.039} \\
\hline No & $313(92.9)$ & $389(96.3)$ & \\
\hline \multicolumn{4}{|c|}{ Pulmonary embolism: N (\%) } \\
\hline Yes & $42(12.5)$ & $22(5.4)$ & \multirow{2}{*}{.001} \\
\hline No & $295(87.5)$ & $382(94.6)$ & \\
\hline \multicolumn{4}{|c|}{ Death $^{c}$} \\
\hline Yes & $5(1.5)$ & $1(0.2)$ & \multirow{2}{*}{$.098^{*}$} \\
\hline No & $332(98.5)$ & $403(99.8)$ & \\
\hline
\end{tabular}

${ }^{\mathrm{a}}$ not including worsening of pre-existing neurological symptoms. ${ }^{\mathrm{b}} \mathrm{N}=505$ patients without pre-operative epilepsy. ${ }^{\mathrm{c}}$ including death from cardiovascular complications and sudden unexplained death. * Fisher's exact test, 2-sided 
Supplementary Table 4. Post-operative hematological parameters of patients with versus without pre-operative embolization.

\begin{tabular}{|c|c|c|c|}
\hline & \multicolumn{2}{|c|}{ Embolization } & \multirow{3}{*}{$\mathrm{P}$} \\
\hline & Yes (group A) & No (group B) & \\
\hline & $\mathrm{N}=336(47.4 \%)$ & $\mathrm{N}=373(52.6 \%)$ & \\
\hline \multicolumn{4}{|c|}{ International normalized ratio } \\
\hline Median & 1.0 & 1.0 & \multirow{2}{*}{.054} \\
\hline Range & $0.8-1.3$ & $0.8-1.4$ & \\
\hline \multicolumn{4}{|c|}{ Thrombin time $\mathrm{a}^{\mathrm{a}}$ : seconds } \\
\hline Median & 14 & 14 & \multirow{2}{*}{.90} \\
\hline Range & $10-200$ & $10-56$ & \\
\hline \multicolumn{4}{|c|}{$\begin{array}{l}\text { Activated prothrombin time }{ }^{\mathrm{b}} \text { : } \\
\text { seconds }\end{array}$} \\
\hline Median & 25 & 26 & \multirow{2}{*}{.092} \\
\hline Range & $17-61$ & $19-59$ & \\
\hline \multicolumn{4}{|c|}{$\begin{array}{l}\text { Partial thromboplastin time }{ }^{\mathrm{c}} \text { : } \\
\text { seconds }\end{array}$} \\
\hline Median & 24 & 23 & \multirow{2}{*}{.57} \\
\hline Range & $18-35$ & $15-47$ & \\
\hline \multicolumn{4}{|c|}{ Fibrinogen $^{\mathrm{d}}$ : grams per liter } \\
\hline Median & 3 & 3 & \multirow{2}{*}{.50} \\
\hline Range & $2-8$ & $1-7$ & \\
\hline \multicolumn{4}{|c|}{ Thrombocytes: N per nanoliter } \\
\hline Median & 203 & 220 & \multirow{2}{*}{.002} \\
\hline Range & $59-526$ & $55-705$ & \\
\hline \multicolumn{4}{|c|}{ Hematocrit: \% } \\
\hline Median & 30.9 & 32.3 & \multirow{2}{*}{$<.001$} \\
\hline Range & $21.0-44.8$ & $20.1-46.4$ & \\
\hline
\end{tabular}

${ }^{\text {a }}$ Data available in $\mathrm{N}=231$ patients; ${ }^{\mathrm{b}}$ Data available in $\mathrm{N}=238$ patients; ${ }^{\mathrm{c}}$ Data available in $\mathrm{N}=456$ patients; ${ }^{\mathrm{d}}$ Data available in $\mathrm{N}=306$ patients 
Supplementary Table 5. Univariate analyses of variables tested in the multivariate models outlined in Table 3.

\begin{tabular}{|l|c|c|}
\hline & \multicolumn{2}{|c|}{ Cardiovascular events } \\
\hline Variable & Odds ratio and 95\% CI & P \\
\hline Group A versus group B & $2.38(1.52-3.70)$ & $<.001$ \\
\hline Demographics & & \\
\hline - Age: $18-54$ versus 55+ & $0.68(0.43-1.06)$ & .091 \\
\hline - Gender: female versus male & $2.56(1.45-4.55)$ & .001 \\
\hline WHO grade: I versus II/III & $1.12(0.65-1.95)$ & .69 \\
\hline Imaging characteristics & $1.39(0.87-2.21)$ & .17 \\
\hline - Max diameter: 40+ versus <40 & $1.01(0.55-1.86)$ & .97 \\
\hline - Multiple meningiomas: yes versus no & $0.82(0.50-1.35)$ & .44 \\
\hline - Radiographic extent of resection: & & .13 \\
\hline gross total versus incomplete & $0.71(0.45-1.11)$ & \\
\hline Cardiovascular risk factors: 0-1 versus 2+ & & \\
\hline
\end{tabular}


Supplementary Table 6. Additional single variables tested in the multivariate model outlined in Table 3.

\begin{tabular}{|l|c|c|}
\hline & \multicolumn{2}{|c|}{ Cardiovascular events } \\
\hline Variable & Odds ratio and 95\% & P \\
\hline Edema: & $1.02(0.63-1.66)$ & .93 \\
$-\quad$ before surgery & $0.89(0.55-1.44)$ & .64 \\
\hline$\quad$ after surgery & $1.31(0.78-2.19)$ & .31 \\
\hline Duration of surgery: $\geq 4 h$ versus $>4 h$ & $2.33(1.40-3.86)$ & .001 \\
\hline Tumor location skull base: yes versus no & $0.44(0.20-0.98)$ & .045 \\
\hline Tumor location parasagittal: yes versus no & $0.78(0.38-1.47)$ & .41 \\
\hline Tumor location convexity: yes versus no & $0.63(0.26-1.54)$ & .32 \\
\hline Tumor location posterior fossa: yes versus no & $0.83(0.51-1.37)$ & .47 \\
\hline Calcification: yes versus no & $1.33(0.81-2.22)$ & .26 \\
\hline Post-operative epilepsy: yes versus no & $1.20(0.76-1.92)$ & .43 \\
\hline Pre-operative neurological deficit: yes versus no & $1.49(0.62-3.62)$ & .37 \\
\hline Intra-axial growth: yes versus no & $1.75(1.05-2.86)$ & .032 \\
\hline Adverse neurological outcome: yes versus no & $0.55(0.29-1.05)$ & .069 \\
\hline Thrombocytes per nl: $250+$ versus $<250$ & $0.81(0.49-1.34)$ & .40 \\
\hline Hematocrit: 0.32+ versus $<0.32$ & & \\
\hline
\end{tabular}


Supplementary Table 7. Multivariate analyses of predictors for adverse neurological outcome 3 months after meningioma resection ${ }^{\mathrm{a}}$.

\begin{tabular}{|c|c|c|c|c|}
\hline & \multicolumn{4}{|c|}{ Adverse neurological outcome } \\
\hline & \multicolumn{2}{|c|}{ Univariate analyses } & \multicolumn{2}{|c|}{ Multivariate analyses } \\
\hline & OR $(95 \%$ CI) & $\mathbf{P}$ & OR (95\% CI) & $\mathbf{P}$ \\
\hline Group $A$ versus group $B$ & $\begin{array}{c}1.64 \\
(1.22-2.17)\end{array}$ & .001 & $\begin{array}{c}1.85 \\
(1.30-2.63)\end{array}$ & .001 \\
\hline \multicolumn{5}{|l|}{ Demographics } \\
\hline - Age: $18-54$ versus 55+ & $\begin{array}{c}1.31 \\
(0.98-1.75)\end{array}$ & .069 & $\begin{array}{c}1.16 \\
(0.83-1.61)\end{array}$ & .38 \\
\hline $\begin{array}{l}\text { - Gender: } \\
\text { female versus male }\end{array}$ & $\begin{array}{c}0.75 \\
(0.55-1.02)\end{array}$ & .064 & $\begin{array}{c}0.79 \\
(0.59-1.13)\end{array}$ & .20 \\
\hline WHO grade: I versus II/III & $\begin{array}{c}0.70 \\
(0.48-1.01)\end{array}$ & .059 & $\begin{array}{c}0.86 \\
(0.55-1.34)\end{array}$ & .49 \\
\hline \multicolumn{5}{|l|}{ Imaging characteristics } \\
\hline $\begin{array}{l}\text { - Max diameter: } \\
40+\text { versus }<40\end{array}$ & $\begin{array}{c}1.06 \\
(0.77-1.45)\end{array}$ & .72 & $\begin{array}{c}1.23 \\
(0.86-1.75)\end{array}$ & .26 \\
\hline $\begin{array}{l}\text { - Multiple meningiomas: } \\
\text { yes versus no }\end{array}$ & $\begin{array}{c}1.59 \\
(1.05-2.38)\end{array}$ & .026 & $\begin{array}{c}1.55 \\
(0.96-2.48)\end{array}$ & .072 \\
\hline $\begin{array}{l}\text { - Radiographic extent of } \\
\text { resection: gross total } \\
\text { versus incomplete }\end{array}$ & $\begin{array}{c}0.54 \\
(0.38-0.76)\end{array}$ & .001 & $\begin{array}{c}0.59 \\
(0.39-0.87)\end{array}$ & .009 \\
\hline
\end{tabular}

${ }^{\text {a }} \mathrm{N}=612$ patients with complete datasets were included 
Supplementary Table 8. Additional single variables tested in the multivariate model outlined in Supplementary Table 7.

\begin{tabular}{|l|c|c|}
\hline \multicolumn{2}{|l|}{} & \multicolumn{2}{|c|}{ Adverse neurological outcome } \\
\hline Variable & OR (95\% CI) & P \\
\hline Edema: & $0.97(0.68-1.38)$ & .85 \\
$\quad-\quad$ before surgery & $1.30(0.92-1.82)$ & .14 \\
\hline after surgery & $1.29(0.90-1.87)$ & .17 \\
\hline Tumor location parasagittal: yes versus no & $0.72(0.47-1.12)$ & .15 \\
\hline Tumor location convexity: yes versus no & $1.02(0.68-1.56)$ & .91 \\
\hline Tumor location posterior fossa: yes versus no & $0.84(0.50-1.85)$ & .54 \\
\hline Calcification: yes versus no & $0.78(0.54-1.14)$ & .19 \\
\hline Post-operative epilepsy: yes versus no & $1.08(0.72-1.61)$ & .72 \\
\hline Pre-operative neurological deficit: yes versus no & $1.18(0.83-1.67)$ & .36 \\
\hline Intra-axial growth: yes versus no & $1.56(0.78-3.13)$ & .21 \\
\hline
\end{tabular}


Table 1. Clinical characteristics of meningioma patients with versus without preoperative tumor embolization.

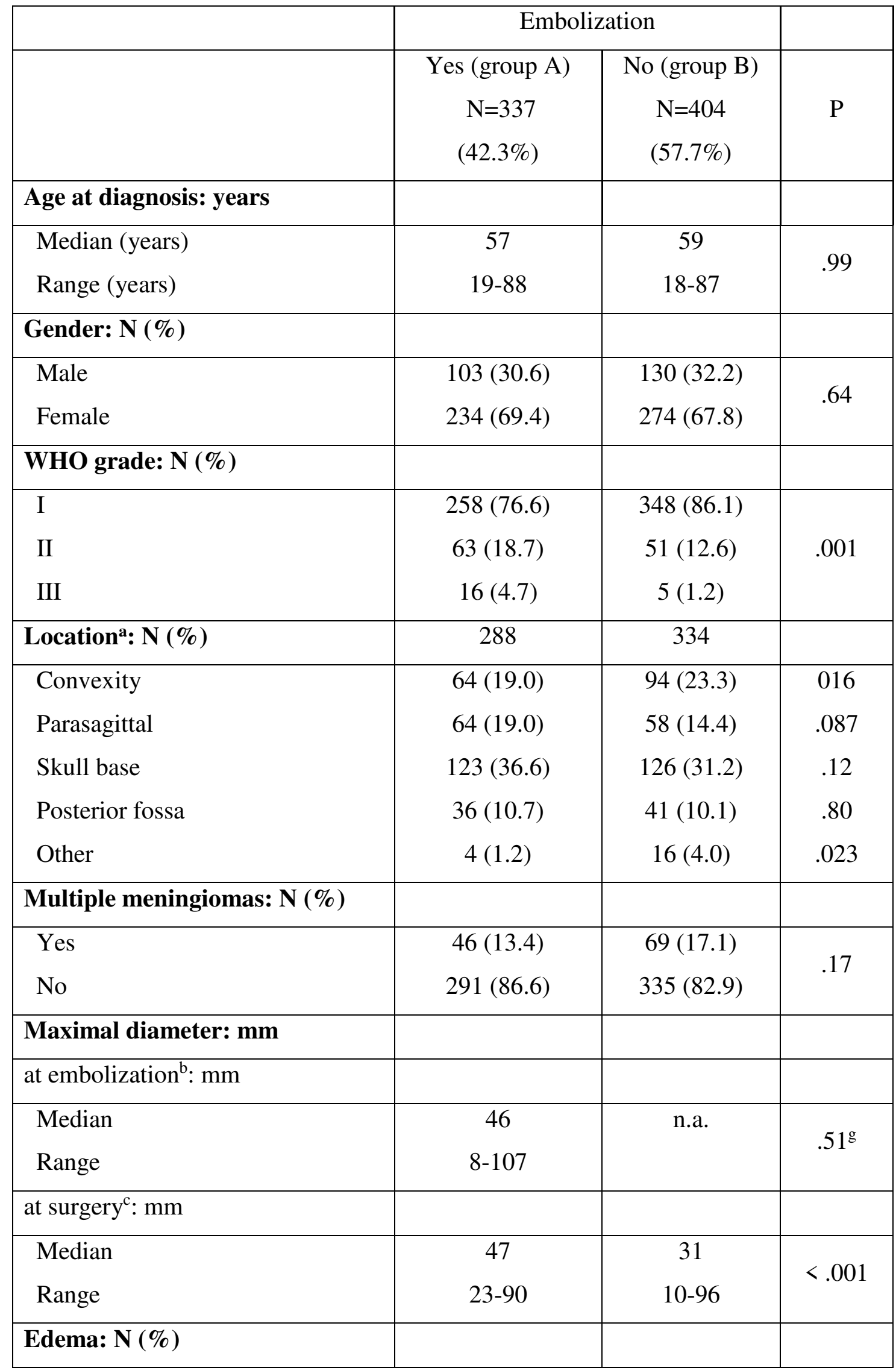




\begin{tabular}{|l|c|c|c|}
\hline at embolization ${ }^{\text {d: }}$ & & & \\
\hline Yes & $169(78.6)$ & n.a. & $<.001^{\mathrm{g}}$ \\
\hline No & $46(21.4)$ & & \\
\hline Yes & & $147(43.2)$ & $<.001$ \\
No & $194(60.1)$ & $193(56.8)$ & \\
\hline Duration of surgeryf: Minutes & $129(39.9)$ & 210 & $<.001$ \\
\hline Median & 270 & $40-755$ & \\
Range & $40-810$ & $84(35.7)$ & \\
\hline Simpson gradeg: N (\%) & $52(24.8)$ & $107(45.5)$ & \\
\hline 1 & $103(49.0)$ & $19(8.1)$ & .011 \\
2 & $18(8.6)$ & $24(10.2)$ & \\
3 & $28(13.3)$ & $1(0.4)$ & \\
4 & $9(4.3)$ & & \\
5 & $250(74.2)$ & $324(80.2)$ & \\
\hline Tumor recurrence during follow- & & & \\
up: N (\%) & & & \\
\hline Yes & & & \\
No & & & \\
\hline
\end{tabular}

${ }^{\mathrm{a}} \mathrm{N}=626$, not including patients with multiple meningiomas, ${ }^{\mathrm{b}}$ documentation available in $\mathrm{N}=215$ patients , ${ }^{\mathrm{c}}$ documentation available in $\mathrm{N}=638$ patients, ${ }^{\mathrm{d}}$ documentation of edema before embolization and before surgery available for comparison in $\mathrm{N}=215$ patients, ${ }^{\mathrm{e}}$ documentation available in $\mathrm{N}=663$ patients, ${ }^{\mathrm{f}}$ documentation available in $\mathrm{N}=445$ patients, ${ }^{\mathrm{g}}$ documentation available in $\mathrm{N}=610$ patients, ${ }^{\mathrm{g}}$ comparison with values in the same patients at surgery 
Table 2. Cardiovascular risk profile of patients with versus without preoperative embolization.

\begin{tabular}{|c|c|c|c|}
\hline & \multicolumn{2}{|c|}{ Embolization } & \multirow[b]{2}{*}{$P$} \\
\hline & $\begin{array}{c}\text { Yes (group A) } \\
\qquad \mathrm{N}=327 \\
(45.5 \%)\end{array}$ & $\begin{array}{c}\text { No (group B) } \\
\quad \mathrm{N}=404 \\
(54.5 \%)\end{array}$ & \\
\hline \multicolumn{4}{|l|}{$\begin{array}{l}\text { Number of cardiovascular } \\
\text { risk factors }\end{array}$} \\
\hline $\begin{array}{l}0-1 \\
>1\end{array}$ & $\begin{array}{l}227(67.4) \\
110(32.6)\end{array}$ & $\begin{array}{l}275(68.1) \\
129(31.9)\end{array}$ & .84 \\
\hline \multicolumn{4}{|l|}{$\begin{array}{l}\text { Cardiovascular risk factors: } \\
\mathrm{N}(\%)\end{array}$} \\
\hline \multirow{6}{*}{$\begin{array}{l}\text { Diabetes } \\
\text { Arterial hypertension } \\
\text { Dyslipidemia } \\
\text { Positive family history } \\
\text { Smoking } \\
\text { Body mass index }>30 \mathrm{~kg} / \mathrm{m} 2\end{array}$} & $31(9.2)$ & $29(7.2)$ & .32 \\
\hline & $100(29.7)$ & $112(27.7)$ & .56 \\
\hline & $24(7.1)$ & $35(8.7)$ & .44 \\
\hline & $71(21.1)$ & $95(23.5)$ & .43 \\
\hline & $79(23.4)$ & $102(25.2)$ & .57 \\
\hline & $78(23.1)$ & $79(19.6)$ & .23 \\
\hline \multicolumn{4}{|l|}{$\begin{array}{l}\text { Pre-operative } \\
\text { cardiovascular events: } \mathbf{N}(\%)\end{array}$} \\
\hline $\begin{array}{l}\text { Yes } \\
\text { No }\end{array}$ & $\begin{array}{c}24(7.1) \\
313(92.9)\end{array}$ & $\begin{array}{c}29(7.2) \\
375(92.8)\end{array}$ & .98 \\
\hline Myocardial infarction & $7(2.1)$ & $7(1.6)$ & .56 \\
\hline Stroke & $8(2.4)$ & $12(2.7)$ & .83 \\
\hline Sinus vein thrombosis & $0(0.0)$ & $0(0.0)$ & n.a. \\
\hline Pulmonary embolism & $6(1.8)$ & $9(2.0)$ & .86 \\
\hline Deep vein thrombosis & $5(1.5)$ & $9(2.0)$ & .62 \\
\hline
\end{tabular}


Table 3. Multivariate analyses of predictors for adverse cardiovascular outcome after meningioma resection ${ }^{\mathrm{a}}$.

\begin{tabular}{|l|c|c|}
\hline & \multicolumn{2}{|c|}{ Cardiovascular events } \\
\hline Multivariate model & Odds ratio and 95\% CI & $\mathrm{P}$ \\
\hline Group A versus group B & $2.38(1.37-4.00)$ & .002 \\
\hline Demographics & & \\
\hline - Age: $18-54$ versus 55+ & $0.76(0.46-1.27)$ & .29 \\
\hline - Gender: female versus male & $2.18(1.17-4.08)$ & .014 \\
\hline WHO grade: I versus II/III & $1.22(0.61-2.43)$ & .58 \\
\hline Imaging characteristics & $1.05(0.63-1.78)$ & .84 \\
\hline - Max diameter: 40+ versus <40 & $1.11(0.56-2.19)$ & .77 \\
\hline - Multiple meningiomas: yes versus no & $0.84(0.48-1.47)$ & .34 \\
\hline - Radiographic extent of resection: & & .14 \\
\hline gross total versus incomplete & $0.68(0.41-1.13)$ & \\
\hline Cardiovascular risk factors: 0-1 versus 2+ & & \\
\hline
\end{tabular}

3

$4{ }^{a} \mathrm{~N}=612$ patients with complete datasets were included 